\title{
Silver Nanoparticles Protects Streptozotocin- induced Hepatotoxicity: a Biochemical and Histopathological Approach
}

QUDSIA BEGUM ( $\nabla$ qudsiahameed93@gmail.com )

University of Karachi https://orcid.org/0000-0002-6373-5691

\section{Tabassum Mahboob}

Department of Biochemistry, University of Karachi

\section{Research}

Keywords: Diabetes, Hepatic Tissue Injury, Antioxidant, Silver Nanoparticles, Histology

Posted Date: August 17th, 2020

DOI: https://doi.org/10.21203/rs.3.rs-45335/v1

License: (c) (i) This work is licensed under a Creative Commons Attribution 4.0 International License.

Read Full License 


\section{Abstract}

Recently in many industries biologically synthesized silver nanoparticles are used as an alternative for their biomedicinal applications predominantly demonstrated as an effective agent in the diabetes treatment. On the other hand, oxidative stress crucially associated with the pathogenesis of diabetic comorbidities like diabetic hepatopathy, which is less common. Thus, the existing study explored the protective role of biologically synthesized silver nanoparticles (AV-AgNPs) against hepatic toxicity persuaded by streptozotocin (STZ) in rats. Wistar male albino rats (200 $\pm 20 \mathrm{~g})$ were segregated into five groups ( $n=10)$ and designated as, Group I-Control (no treatment); Group II-Diabetic control $(35 \mathrm{mg} / \mathrm{kg}$ single dose of streptozotocin, IP); Group III-Diabetic treated with AV-AgNPs (10 mg/kg); Group IV-Diabetic treated with aloe vera leaves extract (AVLE) $(100 \mathrm{mg} / \mathrm{kg})$; Group V-Diabetic treated with glibenclamide (GLB) $(600 \mu \mathrm{g} / \mathrm{kg})$ orally. After treatment of 28 days, animals were euthanized and collected blood and liver specimens for investigations of biochemical, oxidative stress, antioxidant, and histological parameters. Outcomes of the study exhibited that STZ persuades diabetes and hepatic impairments indicated by significant raised $(p<0.05)$ in the levels of blood glucose, alanine aminotransferase (ALT), aspartate aminotransferase (AST), alkaline phosphatase, (ALP), and malondialdehyde (MDA) with decreased catalase (CAT), superoxide dismutase (SOD), and glutathione reductase (GSH) enzymes activities. AV-AgNPs treatment reverted and reestablished the liver enzymes levels, antioxidant enzymes, and histological damages of the liver persuaded by STZ near to normal. In general, these results suggested that AV-AgNPs may have antioxidant potentials and proved to be hepatoprotective therefore, they could be used for the treatment of diabetic hepatopathy and other liver injuries.

\section{Introduction}

Diabetes mellitus (DM) is a common metabolic disease nowadays, categorized via hyperglycemia due to insulin deficit, insulin insensitivity, or both (Saxena and Vikram 2004; American Diabetes Association, 2009). Dysregulation of insulin may develop abnormalities and complications, including nephropathy, peripheral neuropathy, retinopathy, and hepatopathy (Ritz et al. 1990; Hendriksen et al. 1992). Although among all, hepatopathy is possibly less common and least concern area in diabetes complications. Many studies provide evidence that the complication of diabetes may involve the generation of free radicals, thus producing oxidative stress through several paths (Das et al. 2012). To overcome the diabetic complications, new therapeutic drugs are demands of time. WHO reported that about 80 percent of the people ponder folk medicines for dealing with several ailments specifically diabetes and its allied complexities around worldwide, predominantly by considering the use of medicinal plants (Zhang 2002; Nabeel et al. 2010; Patel et al. 2012; Dobs et al. 2013).

The usage of medicinal plants gaining more interest due to owing bioactive constituents; phytochemicals, which hostile oxidative stress (Hannan et al. 2007; Modak et al. 2007; Chauhan et al. 2010; Malviya et al. 2010; Singh 2011; Gajalakshmi et al. 2012; Gholami-Ahangaran et al. 2012; Lavinya et al. 2014;). Aloe vera is an attractive plant that belongs to the Liliaceae family that has many medicinal 
properties. The leaves of Aloe vera have greater antioxidant activity due to the presence of phytochemicals (Hęś et al. 2019).

Silver nanoparticles (AgNPs) gaining more interest among researchers for their potential therapeutic activities due to its minimal toxicity, and higher biodegradability, and bioavailability (Saravanan et al. 2018; Shanmuganathan et al. 2018). The pharmacokinetics of AgNPs shows that the small size nanoparticles deftly interact with the biological system (Pugazhendhi et al. 2018) and synthesized in several ways, in which green synthesis considered most advantageous among other methods since it is cost-effective and provides environmentally-friendly approaches (Saha et al. 2017; Pugazhendhi et al. 2018; Saratale et al. 2018). The use of a plat and plant extract to synthesize nanoparticles become the most viable approach recently in the green synthesis that provides greater potency to nanoparticles for their various uses (Zhang et al. 2016; Jain and Mehata 2017).

Silver nanoparticles synthesized by plant and plant extract have been recognized to possess antimicrobial, hepatoprotective, antidiabetic, and anti-inflammatory properties (Suriyakalaa et al. 2013). However, no data available on the curative effects of biologically synthesized silver nanoparticles against diabetic complications specifically liver injury. Therefore, we intended to study the protective effects of biologically synthesized AgNPs against liver injuries in STZ induced diabetic rat model. So, an aqueous leaf extract of aloe vera and AgNPs derived from its extract were used as a test agent. The method for synthesis of aloe vera derived AgNPs followed with characterization has been published earlier (Begum and Mahboob 2019). The results of the present research help to explore the role of the biologically synthesized silver nanoparticles in liver injuries and could provide the ground for further studies especially to treat diabetes-related complications.

\section{Materials And Methods}

\section{Synthesis \& Characterization of AV-AgNPs}

Silver nanoparticles produced by the method of Chandran et al. (2006) using aqueous aloe vera leaves extract and synthesized silver nanoparticles (AV-AgNPs) were characterized using analytical techniques via Shimadzu UV-visible spectrophotometer (UV-1900, Japan) and scanning electron microscopy (JEOLJapan-JSM 6380A) described in detail in our previously published report (Begum and Mahboob 2019).

\section{Chemicals}

Reagents and chemicals used were analytical grade and procured from the local suppliers (Pakistan) although silver nitrate was acquired from Sigma-Aldrich (USA) and streptozotocin was obtained from Calbiochem (Germany).

\section{Animals}


Healthy, male adult Wistar albino rats $(n=50)$ of the identical age group with a bodyweight of $200( \pm 20 \mathrm{~g})$ procured by the International center for chemical and biological sciences (ICCBS), University of Karachi, accustomed to laboratory environments one-week before experimentation and caged in a moderate temperature maintained room at $23 \pm 4^{\circ} \mathrm{C}$ and 12 hours light-dark cycles. Rats were fed on rodent pellet food and water ad libitum with free access. The experimental procedures were designed by following the world-wide accredited health research extension act (1985).

\section{Induction of diabetes}

To make diabetes model, rats were injected (once) IP, freshly prepared STZ (35 mg/ml/kg in citrate buffer; $\mathrm{pH}=4.5$ ) to overnight-fasted rats (Gayathri and Kannabiran 2008) then, $2 \%$ glucose solution (once) was given to the rats via orally to overcome the hypoglycemic shock and confirmed diabetes later 72 hours of STZ injection (IP) via glucose levels $>250 \mathrm{mg} / \mathrm{dl}$ and proceed for the further experimental protocol.

\section{Study design}

Experimental animals segregated into five groups comprises $(n=10)$ and received the bellow mentioned treatment.

Group-I (C): Control group continue untreated, received a normal rat diet.

Group-II (DC): Diabetic Control group treated with Streptozotocin (STZ) freshly dissolved in chilled citrate buffer at $\mathrm{pH}: 4.5$, given i. p (once) $35 \mathrm{mg} / \mathrm{ml} / \mathrm{kg}$ body weight (Gayathri and Kannabiran 2008).

Group-III (D+AV-AgNPs): Diabetic group received freshly prepared green synthesized silver nanoparticles (AV-AgNPs) orally $10 \mathrm{mg} / \mathrm{ml} / \mathrm{kg}$ body weight dissolved in aqueous media for 28 days daily after induction of diabetes.

Group-IV (D+AVLE): Diabetic group received freshly prepared AV-aliquot orally $100 \mathrm{mg} / \mathrm{ml} / \mathrm{kg}$ body weight for 28 days daily after induction of diabetes.

Group-V (D+GLB): Diabetic group received freshly prepared Glibenclamide orally $600 \mu \mathrm{g} / \mathrm{kg}$ body weight dissolved in aqueous media for 28 days daily after the induction of diabetes (Prabhu et al. 2018).

During the experiment, animals were weighed, monitored individually, and regularly from all experimental groups while \% Change in body weight was calculated via formula (Tabassum and Mahboob 2018) of each rat.

\section{Sample Collection}

Samples of blood and liver were collected later 24 hours of the last dose of administration by decapitating the animals from the neck wound. Plasma separated via centrifugation (2000 rpm) for 20 minutes while after excised liver, trimmed then rinsed with ice-chilled saline, dried, weighed, and a piece of 
tissue for histological examination immersed in $10 \%$ formalin. Whereas, the remaining part kept at $-80{ }^{\circ} \mathrm{C}$ for biochemical analysis.

\section{Liver homogenate preparation}

Liver (1:10 w/v) homogenized with sodium phosphate buffer ( $10 \%$ of $0.1 \mathrm{M}$ at pH-7.4) and centrifuged (1000 rpm) for $10 \mathrm{~min}\left(4^{\circ} \mathrm{C}\right)$ to get supernatant and subsequently added $10 \mu \mathrm{BHT}(0.5 \mathrm{M}$ in acetonitrile) in a fraction to avert further oxidation whereas other part recentrifuged $\left(12000 \mathrm{rpm}\right.$ for $20 \mathrm{~min}$ at $\left.4^{\circ} \mathrm{C}\right)$ for further estimations (Khan et al. 2011).

\section{Estimation of blood glucose}

Blood glucose determined on alternate seven days for 28 days. Rats fasted for 12 hours, blood specimens attained from the tail vein, and measured levels of glucose using a Glucometer (On-Call EZ II ACON Laboratories, Inc., USA). Further, oral glucose tolerance tests (OGTT) executed on day 28. Briefly, animals fasted overnight and, then the concentration of glucose was determined, followed by OGTT via gavage $2 \mathrm{~g} / \mathrm{kg}$ glucose to rats and after the 30 -minute interval for 2 hours concentration of glucose assessed by using a glucometer.

\section{Biochemical analysis}

Biochemical indices of liver function such as aspartate aminotransferase (AST), alanine aminotransferase (ALT), alkaline phosphatase (ALP) were analyzed using a commercially prepared kit (LABKIT, Chemelex, S.A., Canovelles-Barcelona, Spain) as described and resulting values expressed as $\mathrm{U} / \mathrm{L}$.

\section{Lipid peroxidation}

The Malondialdehyde (MDA), is the degree of lipid peroxidation determined by the scheme of Okhawa et al. (1979) based on thiobarbituric acid (TBA) reacting substance interaction with MDA thus produced pink color which was determined by Shimadzu Spectrophotometer (UV-1900, Japan) at $530 \mathrm{~nm}$ absorbance and resulting values were expressed as nmol/gm of tissue.

\section{Superoxide dismutase}

In the liver homogenate, Superoxide dismutase (SOD) activity was assessed by the scheme of Kono (1978) in the cell-free supernatant. the rate of NBT reduction in terms of inhibition (\%) in the reaction mixture was noted per minute at $560 \mathrm{~nm}$ absorbance on Shimadzu Spectrophotometer (UV-1900, Japan) and resulting values expressed as $\mathrm{U} / \mathrm{gm}$ of tissue.

\section{Catalase}

The activity of Catalase (CAT) in liver homogenate was assessed by the scheme of Sinha et al. (1972). In brief, the sample was added to Hydrogen peroxide and phosphate buffer $(\mathrm{pH} ; 7)$ at $100^{\circ} \mathrm{C}$ and 
subsequently added dichromate acetic acid reagent into a fraction of reaction mixture then allowed to boil for 10 minutes, cooled, note the absorbance on Shimadzu Spectrophotometer (UV-1900, Japan) at $570 \mathrm{~nm}$ and resulting values expressed as $\mathrm{nmol} / \mathrm{gm}$ of tissue.

\section{Glutathione reductase}

In the liver homogenate, Glutathione reductase (GSH) activity was measured by the scheme of Carlberg and Mannervik (1985). Briefly, the sample was mixed with BSA, $\beta$-NADPH, potassium phosphate buffer, and oxidized-Glutathione. Note the absorbance of each reaction mixture for $5 \mathrm{~min}$ at $25^{\circ} \mathrm{C}$ by KineticSpectrophotometer (PRIM-500, Germany) at $340 \mathrm{~nm}$ and resulting values expressed as U/gm of tissue.

\section{Histopathology}

Rats liver removed quickly, washed with phosphate-buffered saline to eradicate debris, and a piece of tissue immersed in $10 \%$ formalin. About $5 \mu \mathrm{m}$ tissue slices implanted in molten paraffin wax, stained with hematoxylin and eosin (H\&E), and tissue morphology was analyzed by light microscopy at 10x magnification.

\section{STATISTICAL ANALYSIS}

Data exhibited as mean \pm SD $(n=10)$ considered significant when $p<0.05$ using ANOVA (One-way) followed by post hoc test (Tukey's) using IBM-SPSS version 22 (IBM, Anmork, NY, USA).

\section{Results}

\section{Change in body weights (\%), liver weight, and relative liver weight}

Results in Table 1 displayed the change in body weight, liver weight, and relative liver weight in all groups. A considerable decrease in percent change in body weight was found in streptozotocin-induced diabetic rats in contrast with the control $(p<0.05)$. Similarly, a significantly improved in percent change in body weight was also perceived in all diabetic treated groups ( $D+A V-A g N P s, D+A V L E$, and $D+G L B$ ) compared with diabetic control groups. Further, the significant gain in liver weight and relative liver weight $(P<0.05)$ observed in the streptozotocin-induced diabetic control contrast with the control. Though, a significant decrease $(P<0.05)$ in liver weight and relative liver weight noticed in all treated groups like $D+A V-A g N P s$, $D+A V L E$, and $D+G L B$ in contrast with the diabetic control group.

\section{Fasting and random blood glucose}

Results in Table 2 exhibited the AV-AgNPs treatment effects on blood glucose levels both random and fasting in all groups. Both blood glucose levels (random and fasting) were substantially elevated $(p<0.05)$ in streptozotocin-induced diabetic rats and all diabetic treated groups (D+AV-AgNPs, D+AVLE, and $D+G L B)$ compared with control $(p<0.05)$. However, all diabetic treated groups significantly declined $(p<0.05)$ blood glucose of both fasting and random levels compared with diabetic control. 


\section{Glucose tolerance test}

Results in Table 3 exhibited the AV-AgNPs treatment on glucose tolerance tests in all groups. The result revealed oral glucose administration at 30 min interval for 2 hours (0-120 min) for tolerance test, glibenclamide improved glucose tolerance in the diabetic treated group. Likewise, diabetic treated groups $(D+A V-A g N P s, D+A V L E$, and $D+G L B)$ significantly reduced blood glucose levels $(p<0.05)$ at 120 min compared with control and diabetic control. Moreover, the result showed better tolerance in D+AV-AgNPs compared with D+AVLE.

\section{Hepatic function markers}

Results in Table 4 present the AV-AgNPs treatment effects on hepatic functions in all groups. In the diabetic control and treated groups ( $D+A V-A g N P s, D+A V L E$, and $D+G L B)$ hepatic function markers like ALP, AST, and ALT were elevated considerably in contrast with control $(p<0.05)$. However, the diabetic treated groups $(D+A V-A g N P s, D+A V L E$, and $D+G L B)$ restored the ALP, AST, and ALT levels $(p<0.05)$ in contrast with diabetic control.

\section{Hepatic oxidative stress and antioxidant enzymes}

Figures 1 to 4 illustrated the hepatic oxidative stress and antioxidant enzymes (MDA, SOD, CAT, and GSH) in control and all treated groups. Hepatic tissue MDA level markedly raised $(p<0.05)$ in the diabetic group compared with control. However, diabetic rats treated with AV-AgNPs, AVLE, and GLB markedly reduced MDA $(p<0.05)$ as compared with diabetic control. On the other hand, significant decreased $(p<0.05)$ observed in the level of SOD in the hepatic tissues of diabetic rats. Further, the administration of AVAgNPs, AVLE, and GLB to diabetic rats significantly improved $(p<0.05)$ antioxidant enzyme SOD as compared with diabetic control. In a similar trend, the level of CAT remarkably reduced significantly $(p<0.05)$ in the hepatic tissues of diabetic rats. While, all treated diabetic rats ( $D+A V-A g N P s, D+A V L E$, and $D+G L B)$ significantly improved $(p<0.05)$ antioxidant enzyme CAT as compared with diabetic control. Likewise, a remarkably reduced $(p<0.05)$ level of $\mathrm{GSH}$ observed in the hepatic tissues of diabetic rats. But the diabetic treated rats with AV-AgNPs, AVLE, and GLB significantly improved $(p<0.05)$ antioxidant enzyme GSH as compared with diabetic control.

\section{Histology of hepatic tissues in control and treated groups}

The histopathological screening of hepatic tissues of the normal control group displayed normal architecture of hepatic tissue with arranged hepatocytes and central vein (CV) along with the sinusoidal spaces (Figure 5A). In STZ induced diabetic control group, hepatic tissues indicated congestion in a central vein (CV), loss of normal central to the portal relationship, and Infiltration of inflammatory cells (Figure 5B). Administration of AV-AgNPs and AVLE respectively after induction of diabetes induced by STZ, protected against STZ induced hepatotoxicity (Figure 5C-E) thereby suggesting a protective role of AV-AgNPs against diabetic induced hepatotoxicity. 


\section{Discussion}

The existing study provides the role of AV-AgNPs on hepatic toxicity persuaded by streptozotocin in rats. Present results exhibited that treated rats with streptozotocin (STZ) caused various pathophysiological consequences such as derangements of body weight, liver weight, liver functional markers, elevated blood glucose (both fasting and random), elevated MDA, depletion of antioxidant enzymes, and disturbed liver histology. These observations corroborate by earlier reports on streptozotocin-induced diabetes (Gayathri and Kannabiran 2008). Streptozotocin (STZ) is extensively used to persuade diabetes in investigational rats by targeting $\beta$-cell of islets of Langerhans through GLUT-2 (glucose transporter) leads to DNA alkylation, and necrosis consequently declined insulin, and progress hyperglycemia (Szkudelski 2001).

In the present study, streptozotocin persuaded diabetes significantly endorsed a marked reduction in percent change in body weight contrast with control (Table 1). The effects of silver nanoparticles on rats reliant on AgNPs concentration, the route by which it administered, and the duration of treatment (Zhang et al. 2016). Earlier studies found that the AgNPs did not have any adverse effects on the body weights of the animals following its oral administration (Suriyakalaa et al. 2013; Jain and Mehata 2017). The possible mechanism associated with AV-AgNPs antioxidant ability which counteracting the generation of free radicals via STZ in the pancreas (Begum and Mahboob 2019). Also, it can diminish the STZ persuaded toxicity and potentiates $\beta$-cells to proliferate more insulin secretion. The augmented insulin secretion leads to promote glucose consumption through extrahepatic tissues thus decreases blood glucose.

The liver is the primary organ, accounting for the metabolism, detoxification, storage, and elimination of byproducts and their metabolites (Francis et al. 2003). It also aids in sustaining blood glucose levels via metabolic pathways like glycogenolysis and gluconeogenesis also in the post-absorptive state. Hyperglycemic condition distresses the liver and liable them to damage. ALT, ALP, and AST (Ramaiah 2007) are the reliable indicators of liver function, which remain within the cells under normal physiological conditions whereas they are leaking into the serum upon cell damage (Johnston 1999). In our study, STZ persuaded hepatic toxicity consequently alleviated the levels of ALT, ALP, and AST in serum (Felig et al. 1970; Zhang et al. 2019). These markers were found to significantly improve after AVAgNPs administration (Chatterjee et al. 2011; Tabassum and Mahboob 2018) which is consistent in our study (Table 3). The decrease in serum transaminases near to normal after the treatment of AV-AgNPs specifies a possible revival of hepatocytes and a healing impact on the hepatic parenchyma (Seif 2016). Overall restoration perceived in AV-AgNPs treated group represents its therapeutic effect. Besides this, lipid peroxidation may also attribute to the extreme ROS production which is mechanistically involved in hepatic impairment (Akhgari et al. 2003).

It has been well documented that STZ induced diabetes associated with ROS generation and lipid peroxidation (Dakhil 2017). While the extreme formation of free-radical controls by antioxidant enzymes that protect cell membranes in all tissues to divergent oxidative injury including hepatic tissues (Pham- 
Huy et al. 2008). Noticeable increment in the level of MDA (Figure-1) followed with substantial diminution in activities of SOD, CAT, and GSH in hepatic tissues in STZ persuaded toxicity (Figure-2 to Figure-4) revealed in the present study which was overcome by administration of AV-AgNPs. Though, findings of the existing study are consistent with the earlier reports which revealed that STZ imposed liver dysfunction via oxidative stress followed by lipid peroxidation and silver nanoparticles have the ability to deal with it (Heidary et al. 2014; Afifi and Abdelazim 2015).

Evidence suggested that the cell follows an adaptive mechanism to normalize stress exposure by altering oxidative stress and antioxidant enzymes (Adeyemi and Faniyan 2014). An earlier study reported that micro-sized silver nanoparticles were the most effective antioxidant at smaller doses (Rajasekaran et al. 2005; Schluesener and Schluesener 2013) and prevent toxicity via decrease accumulations. In the present study, we use a smaller dose $(10 \mathrm{mg} / \mathrm{kg})$ of $20-24 \mathrm{~nm}$ particle size, that supports our findings by exhibiting beneficial therapeutic effects. The mechanism of silver nanoparticles being antioxidant is due to the existence of active compounds present in AVLE which capped silver nanoparticles (Yadav and Dixit 2003). Evidence can elucidate the antioxidant proficiency of AV-AgNPs to restores the hepatic injury allied with oxidative stress.

Histopathology of livers tissues of the control group exhibited normal hepatic tissue architecture with arranged hepatocytes and central vein (CV) along with the sinusoidal spaces $(5 \mathrm{~A})$. Whereas, the hepatic architecture of the STZ intoxicated group displayed congestion in a central vein (CV), loss of normal central to the portal relationship, and Infiltration of inflammatory cells (5B). Administration of AV-AgNPs and AVLE after induction of diabetes induced by STZ was brought back to near normal architecture of hepatic tissues indicating substantial protection of the liver (Figure 5C to 5E) against diabetic induced hepatotoxicity (Figure 5C to 5E). The histological outcomes support biochemical findings in the present study. Similar observations in liver tissues were elucidated in earlier studies (Chatterjee et al. 2011; Tabassum and Mahboob 2018).

The capability of a drug to diminish damages or to reserve the normal functioning of the liver later toxicity induction elucidates its hepato-curative effect (Nagaich et al. 2016). AgNPs produced by plant extracts provides synergistic effects like antioxidant effect (Keshari et al. 2020). Outcomes attained by biochemical and histological investigations imply that AV-AgNPs emphatically protect STZ intoxication. Lipid peroxidation upsurges via failure in the antioxidant system leading towards the loss of normal physiological functioning of the liver at the cellular level (Akhgari et al. 2003). Consequently, the antioxidative and free radical scavenging competence of AV-AgNPs might crucially involve in the restoration of the parameters (biochemical and histological) near to normal in treated groups making AVAgNPs a strong contender for numerous therapeutic claims like hepatocurative.

\section{Conclusion}

Treatment with AV-AgNPs perceived as a potent antioxidative agent to reinstate the hepatic toxicity persuaded by STZ hence, restored the body and relative weights, hepatic biomarkers, lipid peroxidation, 
and activities of antioxidant enzymes. Based on results it is concluded that AV-AgNPs can be effectively used to diminish oxidative stress which is the main progressive agent for developing diabetic comorbidities and other diseases via its antioxidant possessions. Moreover, mechanistic evidence is mandatory to elucidate a particular mechanism.

\section{Abbreviations}

DM: Diabetes mellitus; AV-AgNPs: Biologically synthesized silver nanoparticles; STZ: Streptozotocin; AVLE: Aloe vera leaves extract; GLB: Glibenclamide; ALT: Alanine aminotransferase; AST: Aspartate aminotransferase; ALP: Alkaline phosphatase; MDA: Malondialdehyde; CAT: Catalase; SOD: Superoxide dismutase; GSH: Glutathione reductase; TBA: Thiobarbituric acid; NBT: Nitroblue tetrazolium; BSA: Bovine serum albumin; $\beta$-NADPH: $\beta$-Nicotinamide adenine dinucleotide 2'-phosphate reduced tetrasodium salt.

\section{Declarations}

Ethics approval, consent to participate and consent for publication

Non-applicable.

\section{Availability of data and materials}

All data generated or analyzed during this study are included in this article.

\section{Competing interests}

The authors declare that they have no competing interests.

\section{Funding}

No financial support received by the author(s).

\section{Authors' contributions}

Qudsia Begum conceived and coordinated the study, performed the experiments, analyzed the experimental results, and wrote and edited the paper. Tabassum Mahboob conceived and coordinated the study, validated the experimental design, and edited the paper. Both authors read and approved the final manuscript.

\section{Acknowledgments}

Non-applicable.

\section{References}


1. Adeyemi OS, Faniyan TO (2014) Antioxidant status of rats administered silver nanoparticles orally. J Taibah Univ Medical Sci 9(3):182-186.

2. Afifi M, Abdelazim AM (2015) Ameliorative effect of zinc oxide and silver nanoparticles on antioxidant system in the brain of diabetic rats. Asian Pac J Trop Biomed 5(10):874-877.

3. Akhgari M, Abdollahi M, Kebryaeezadeh A, Hosseini R, Sabzevari O (2003) Biochemical evidence for free radical induced lipid peroxidation as a mechanism for subchronic toxicity of malathion in blood and liver of rats. Hum Exp Toxicol 22(4): 205-211.

4. American Diabetes Association (2009) Diagnosis and classification of diabetes mellitus. Diabetes care 32 (Supplement 1): S62-S67.

5. Begum Q, Mahboob T (2019) Evaluation of antioxidant activity of biologically synthesized silver nanoparticles using Aloe vera. Int J Biol Biotech 16 (3): 641-653.

6. Carlberg I, Mannervik B (1985) Glutathione reductase. Methods Enzymol 113: 484-490.

7. Chatterjee S, Dey A, Dutta R, Dey S, Acharya K (2011) Hepatoprotective effect of the ethanolic extract of Calocybe indica on mice with $\mathrm{CCl}_{4}$ hepatic intoxication. Int J Pharm Tech Res 3(4):2162-2168.

8. Chauhan A, Sharma PK, Srivastava P, Kumar N, Dudhe R (2010) Plants having potential antidiabetic activity: a review. Der Pharm Lett 2(3):369-387.

9. Dakhil AS (2017) Biosynthesis of silver nanoparticle (AgNPs) using Lactobacillus and their effects on oxidative stress biomarkers in rats. J King Saud Univ Sci 29(4):462-467.

10. Das J, Roy A, Sil PC (2012) Mechanism of the protective action of taurine in toxin and drug induced organ pathophysiology and diabetic complications: a review. Food Funct 3(12):1251-1264.

11. Dobs AS, Goldstein BJ, Aschner P, Horton ES, Umpierrez GE, Duran L, et al (2013) Efficacy and safety of sitagliptin added to ongoing metformin and rosiglitazone combination therapy in a randomized placebo-controlled 54-week trial in patients with type 2 diabetes. J Diabetes 5(1):68-79.

12. Felig P, Marliss E, Ohman JL, Cahill GF (1970) Plasma amino acid levels in diabetic ketoacidosis. Diabetes 19(10):727-729.

13. Francis GA, Fayard E, Picard F, Auwerx J (2003) Nuclear receptors and the control of metabolism. Annu Rev Physiol 65(1):261-311.

14. Gajalakshmi S, Vijayalakshmi S, Devi RV (2012) Phytochemical and pharmacological properties of Annona muricata: a review. Int J Pharm Pharm Sci 4(2):3-6.

15. Gayathri M, Kannabiran K (2008) Antidiabetic and ameliorative potential of Ficus bengalensis bark extract in streptozotocin induced diabetic rats. Indian J Clin Biochem 23(4):394-400.

16. Gholami-Ahangaran M, Bahmani M, Zia-Jahromi N (2012) Comparative and evaluation of anti-leech (Limnatis nilotica) effect of olive (Olea europaea L.) with levamisol and tiabendazole. Asian Pac $\mathrm{J}$ Trop Dis 2: S101-S103.

17. Hannan JM, Marenah L, Ali L, Rokeya B, Flatt PR, Abdel-Wahab YH (2007)Insulin secretory actions of extracts of Asparagus racemosus root in perfused pancreas, isolated islets and clonal pancreatic $\beta$ cells. J Endocrinol 192(1):159-168. 
18. Heidary T, Shayesteh FK, Ghasemi H, Zijoud SM, Ranjbar A (2014) Effects of silver nanoparticle (AgNP) on oxidative stress, liver function in rat: hepatotoxic or hepatoprotective?. Issues Bio Sci Pharm Res 2(5): 40-44.

19. Hendriksen PH, Oey PL, Wieneke GH, Bravenboer B, Banga JD (1992) Subclinical diabetic neuropathy: similarities between electrophysiological results of patients with type 1 (insulindependent) and type 2 (non-insulin-dependent) diabetes mellitus. Diabetologia 35(7):690-695.

20. Hęś M, Dziedzic K, Górecka D, Jędrusek-Golińska A, Gujska E (2019) Aloe vera (L.) Webb.: Natural Sources of Antioxidants-A Review. Plant Foods Hum Nutr; 18:1-11.

21. Jain S, Mehata MS (2017) Medicinal plant leaf extract and pure flavonoid mediated green synthesis of silver nanoparticles and their enhanced antibacterial property. Sci Rep 7(1):1-13.

22. Johnston DE (1999) Special considerations in interpreting liver function tests. Am Fam Physician 59: 2223-2232.

23. Keshari AK, Srivastava R, Singh P, Yadav VB, Nath G (2020) Antioxidant and antibacterial activity of silver nanoparticles synthesized by Cestrum nocturnum. J Ayurveda Integr Med 11(1):37-44.

24. Khan MS, Khan MK, Siddiqui MH, Arif JM (2011) An in vivo and in silico approach to elucidate the tocotrienol-mediated fortification against infection and inflammation induced alterations in antioxidant defense system. Eur Rev Med Pharmacol Sci 15(8):916-930.

25. Kono $Y$ (1978) Generation of superoxide radical during autoxidation of hydroxylamineand an assay for superoxide dismutase. Arch Biochem Biophys 186(1): 189-195.

26. Lavinya BU, Akalya JL, Srujana KS, Sabina EP, Rajeswari VD (2014) Appraisal of the in vitro antibacterial and anti-oxidant potential of the leaf extracts of Cadaba fruticosa. Asian J Pharm Clin Res 7:118-120.

27. Malviya N, Jain S, Malviya SA (2010) Antidiabetic potential of medicinal plants. Acta Pol Pharm 67(2):113-118.

28. Modak M, Dixit P, Londhe J, Ghaskadbi S, Devasagayam TP (2007) Recent advances in Indian herbal drug research guest editor: Thomas Paul Asir Devasagayam Indian herbs and herbal drugs used for the treatment of diabetes. J Clin Biochem Nutr 40(3):163-173.

29. Nabeel MA, Kathiresan K, Manivannan S (2010) Antidiabetic activity of the mangrove species Ceriops decandra in alloxan-induced diabetic rats. J Diabetes 2(2):97-103.

30. Nagaich U, Gulati N, Chauhan S (2016) Antioxidant and antibacterial potential of silver nanoparticles: biogenic synthesis utilizing apple extract. J pharm 2016.

31. Nagalekshmi R, Menon A, Chandrasekharan DK, Nair CK (2011) Hepatoprotective activity of Andrographis paniculata and Swertia chirayita. Food Chem Toxicol 49(12):3367-3373.

32. Okhawa H, Ohishi N, Yagi K (1979) Reaction of linoleic acid hydroperoxides with thiobarbituric acids. Anal Biochem 95(2): 351-354.

33. Patel DK, Prasad SK, Kumar R, Hemalatha S (2012) An overview on antidiabetic medicinal plants having insulin mimetic property. Asian Pac J Trop Biomed 2(4):320-330. 
34. Pham-Huy LA, He H, Pham-Huy C (2008) Free radicals, antioxidants in disease and health. Int J Biomed Sci 4(2):89.

35. Prabhu S, Vinodhini S, Elanchezhiyan C, Rajeswari D (2018) Evaluation of antidiabetic activity of biologically synthesized silver nanoparticles using Pouteria sapota in streptozotocin-induced diabetic rats. J Diabetes 10(1):28-42.

36. Pugazhendhi A, Edison TN, Karuppusamy I, Kathirvel B (2018) Inorganic nanoparticles: a potential cancer therapy for human welfare. Int J Pharm 539(1-2):104-111.

37. Pugazhendhi A, Prabakar D, Jacob JM, Karuppusamy I, Saratale RG (2018) Synthesis and characterization of silver nanoparticles using Gelidium amansii and its antimicrobial property against various pathogenic bacteria. Microb Pathog 114:41-45.

38. Rajasekaran S, Sivagnanam K, Subramanian S (2005) Modulatory effects of Aloe vera leaf gel extract on oxidative stress in rats treated with streptozotocin. J pharm Pharmacol 57(2):241-246.

39. Ramaiah SK (2007) A toxicologist guide to the diagnostic interpretation of hepatic biochemical parameters. Food Chem Toxicol 45: 1551-1557.

40. Ritz E, Hasslacher C, Tschöpe W (1990) Diabetic nephropathy-are there differences between type I and type II?. Miner Electrolyte Metab 16(1):69-72.

41. Saha J, Begum A, Mukherjee A, Kumar S (2017) A novel green synthesis of silver nanoparticles and their catalytic action in reduction of Methylene Blue dye. Sustain Environ Res 27(5):245-250.

42. Saratale RG, Saratale GD, Shin HS, Jacob JM, Pugazhendhi A, Bhaisare M, et al (2018) New insights on the green synthesis of metallic nanoparticles using plant and waste biomaterials: current knowledge, their agricultural and environmental applications. Environ Sci Pollut Res 25(11):1016410183.

43. Saravanan M, Barik SK, MubarakAli D, Prakash P, Pugazhendhi A (2018) Synthesis of silver nanoparticles from Bacillus brevis (NCIM 2533) and their antibacterial activity against pathogenic bacteria. Microb Pathog 116: 221-226.

44. Saxena A, Vikram NK (2004) Role of selected Indian plants in management of type 2 diabetes: a review. J Altern Complement Med 10(2):369-378.

45. Schluesener JK, Schluesener HJ (2013) Nanosilver: application and novel aspects of toxicology. Arch Toxicol 87(4):569-576.

46. Seif HS (2016) Physiological changes due to hepatotoxicity and the protective role of some medicinal plants. Beni-Suef Univ J basic Appl Sci 5(2):134-146.

47. Shanmuganathan R, MubarakAli D, Prabakar D, Muthukumar H, Thajuddin N, Kumar SS, Pugazhendhi A (2018) An enhancement of antimicrobial efficacy of biogenic and ceftriaxoneconjugated silver nanoparticles: green approach. Environ Sci Pollut Res 25(11):10362-10370.

48. Singh LW (2011) Traditional medicinal plants of Manipur as anti-diabetics. J Med Plant Res 5(5):677-687.

49. Sinha KA (1972) Colorimetric assay of catalase. Anal Biochem 47(2): 389-394. 
50. Suriyakalaa U, Antony JJ, Suganya S, Siva D, Sukirtha R, Kamalakkannan S, et al (2013) Hepatocurative activity of biosynthesized silver nanoparticles fabricated using Andrographis paniculate. Colloids Surf B 102:189-194.

51. Szkudelski T (2001) The mechanism of alloxan and streptozotocin action in B cells of the rat pancreas. Physiol Res 50(6): 537-546.

52. Tabassum A, Mahboob T (2018) Role of peroxisome proliferator-activated receptor-gamma activation on visfatin, advanced glycation end products, and renal oxidative stress in obesity-induced type 2 diabetes mellitus. Hum Exp Toxicol 37(11):1187-1198.

53. Yadav NP, Dixit VK (2003) Hepatoprotective activity of leaves of Kalanchoe pinnata Pers. J Ethnopharmacol 86(2-3):197-202.

54. Zhang H, Jacob JA, Jiang Z, Xu S, Sun K, Zhong Z, et al (2019) Hepatoprotective effect of silver nanoparticles synthesized using aqueous leaf extract of Rhizophora apiculata. Int $\mathrm{J}$ Nanomedicine 14:3517.

55. Zhang X (2002) WHO traditional medicine strategy 2002-2005. Geneva, Switzerland: World Health Organization.

56. Zhang XF, Liu ZG, Shen W, Gurunathan S (2016) Silver nanoparticles: synthesis, characterization, properties, applications, and therapeutic approaches. Int J Mol Sci 17:1534.

\section{Tables}

Table 1 Effects of AV-AgNPs Treatment on Change in Body Weights, Organ Weight, And Relative Organ Weight

\begin{tabular}{|llllll|}
\hline Parameters & C $^{\mathrm{a}}$ & DC $^{\mathrm{b}}$ & D+AV-AgNPs $^{\mathrm{C}}$ & D+AVLE $^{\mathrm{d}}$ & D+GLB $^{\mathrm{e}}$ \\
\hline Change in body weight (\%) & 10.31 & -16.72 & 8.84 & 9.61 & 4.55 \\
& \pm 3.81 & $\pm 7.64^{\mathrm{a}}$ & $\pm 1.50^{\mathrm{b}}$ & $\pm 2.86^{\mathrm{b}}$ & $\pm 4.14^{\mathrm{b}}$ \\
\hline Liver weight (g) & 5.94 & 7.76 & 6.21 & 6.67 & 6.05 \\
& \pm 0.34 & $\pm 0.51^{\mathrm{a}}$ & $\pm 0.42^{\mathrm{b}}$ & $\pm 0.61^{\mathrm{ab}}$ & $\pm 0.21^{\mathrm{b}}$ \\
\hline Relative liver weight (\%) & 2.72 & 3.90 & 2.62 & 2.63 & 2.55 \\
& \pm 0.32 & $\pm 0.23^{\mathrm{a}}$ & $\pm 0.24^{\mathrm{b}}$ & $\pm 0.27^{\mathrm{b}}$ & $\pm 0.12^{\mathrm{b}}$ \\
\hline
\end{tabular}

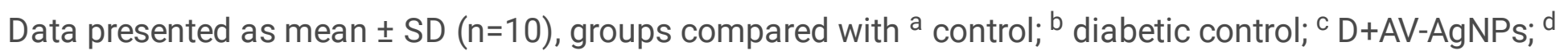
$D+A V L E,{ }^{e} D+G L B$; result considered significant when $p<0.05$ using ANOVA (One-way) followed by post hoc test (Tukey's).

Table 2 Effects of AV-AgNPs Treatment on Fasting Blood Glucose and Random Blood Glucose 


\begin{tabular}{|llllll|}
\hline Parameters & C $^{\mathrm{a}}$ & DC $^{\mathrm{b}}$ & D+AV-AgNPs $^{\mathrm{c}}$ & D+AVLE $^{\mathrm{d}}$ & D+GLB $^{\mathrm{e}}$ \\
\hline Fasting Blood Glucose (mg/dl) & 84.45 & 328.63 & 119.37 & 140.37 & 128.47 \\
& \pm 8.25 & $\pm 25.09^{\mathrm{a}}$ & $\pm 9.96^{\mathrm{ab}}$ & $\pm 11.95^{\mathrm{abc}}$ & $\pm 9.34^{\mathrm{ab}}$ \\
\hline Random Blood Glucose (mg/dl) & 118.49 & 340.3 & 130.73 & 149.35 & 145.52 \\
& \pm 8.83 & $\pm 15.40^{\mathrm{a}}$ & $\pm 11.11^{\mathrm{b}}$ & $\pm 11.13^{\mathrm{abc}}$ & $\pm 20.39^{\mathrm{ab}}$ \\
\hline
\end{tabular}

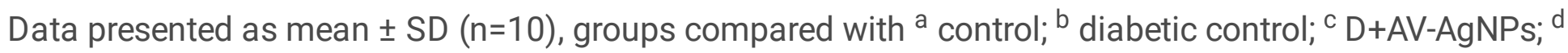
$D+A V L E,{ }^{e} D+G L B$; result considered significant when $p<0.05$ using ANOVA (One-way) followed by post hoc test (Tukey's).

Table 3 Effects of AV-AgNPs Treatment on Glucose Tolerance Test

\begin{tabular}{|c|c|c|c|c|c|}
\hline Parameters & $c^{a}$ & $D C^{b}$ & $D+A V-A g N P s^{c}$ & $\mathrm{D}+\mathrm{AVLE}^{\mathrm{d}}$ & $\mathrm{D}+\mathrm{GLB}^{\mathrm{e}}$ \\
\hline \multirow[t]{2}{*}{$0 \mathrm{~min}$} & 78.43 & 263.44 & 254.9 & 258.25 & 262.71 \\
\hline & \pm 5.30 & $\pm 10.34^{\mathrm{a}}$ & $\pm 5.70^{\mathrm{a}}$ & $\pm 3.61^{\mathrm{a}}$ & $\pm 9.82^{\mathrm{a}}$ \\
\hline \multirow[t]{2}{*}{$30 \mathrm{~min}$} & 91.27 & 281.55 & 265.48 & 279.62 & 286.59 \\
\hline & \pm 5.11 & $\pm 13.72^{\mathrm{a}}$ & $\pm 8.66^{\mathrm{ab}}$ & $\pm 11.30^{\mathrm{a}}$ & $\pm 6.56^{\mathrm{ac}}$ \\
\hline \multirow[t]{2}{*}{$60 \mathrm{~min}$} & 97.78 & 331.57 & 283.66 & 299.11 & 295.93 \\
\hline & \pm 5.32 & $\pm 27.24^{a}$ & $\pm 11.44^{\mathrm{ab}}$ & $\pm 12.42^{\mathrm{ab}}$ & $\pm 6.17^{\mathrm{ab}}$ \\
\hline \multirow[t]{2}{*}{$90 \min$} & 89.53 & 305.72 & 217.14 & 251.53 & 231.27 \\
\hline & \pm 4.63 & $\pm 17.15^{\mathrm{a}}$ & $\pm 33.83^{\mathrm{ab}}$ & $\pm 6.83^{a b c}$ & $\pm 12.31^{\mathrm{ab}}$ \\
\hline \multirow[t]{2}{*}{$120 \mathrm{~min}$} & 83.25 & 284.54 & 176.63 & 196.32 & 187.41 \\
\hline & \pm 6.48 & $\pm 17.75^{\mathrm{a}}$ & $\pm 12.7^{\mathrm{ab}}$ & $\pm 36.31^{\mathrm{ab}}$ & $\pm 11.94^{\mathrm{ab}}$ \\
\hline
\end{tabular}

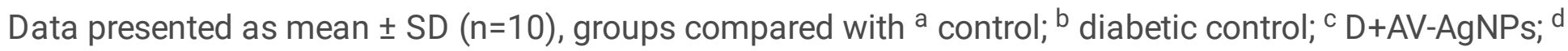
$D+A V L E,{ }^{e} D+G L B$; result considered significant when $p<0.05$ using ANOVA (One-way) followed by post hoc test (Tukey's).

Table 4 Effects of AV-AgNPs Treatment on Liver Functions 


\begin{tabular}{|llllll|}
\hline Parameters & $\mathbf{C}^{\mathrm{a}}$ & DC $^{\mathrm{b}}$ & D+AV-AgNPs $^{\mathrm{c}}$ & D+AVLE $^{\mathrm{d}}$ & D+GLB $^{\mathbf{e}}$ \\
\hline ALT (U/I) & 29.81 & 62.26 & 36.17 & 40.17 & 33.73 \\
& \pm 1.51 & $\pm 2.39^{\mathrm{a}}$ & $\pm 4.28^{\mathrm{ab}}$ & $\pm 3.37^{\mathrm{ab}}$ & $\pm 2.14^{\mathrm{bd}}$ \\
AST (U/I) & 39.46 & 78.82 & 50.74 & 59.04 & 42.74 \\
& \pm 5.72 & $\pm 6.89^{\mathrm{a}}$ & $\pm 3.88^{\mathrm{ab}}$ & $\pm 6.91^{\mathrm{abc}}$ & $\pm 5.35^{\mathrm{bed}}$ \\
\hline ALP (U/I) & 62.81 & 149.76 & 81.92 & 94.22 & 66.81 \\
& \pm 6.21 & $\pm 11.73^{\mathrm{a}}$ & $\pm 8.57^{\mathrm{ab}}$ & $\pm 9.13^{\mathrm{abc}}$ & $\pm 10.49^{\mathrm{bcd}}$ \\
\hline
\end{tabular}

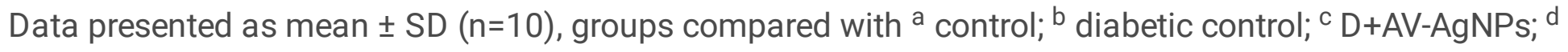
$D+A V L E,{ }^{e} D+G L B$; result considered significant when $p<0.05$ using ANOVA (One-way) followed by post hoc test (Tukey's).

\section{Figures}

\section{Hepatic MDA (nmol/gm of tissue)}

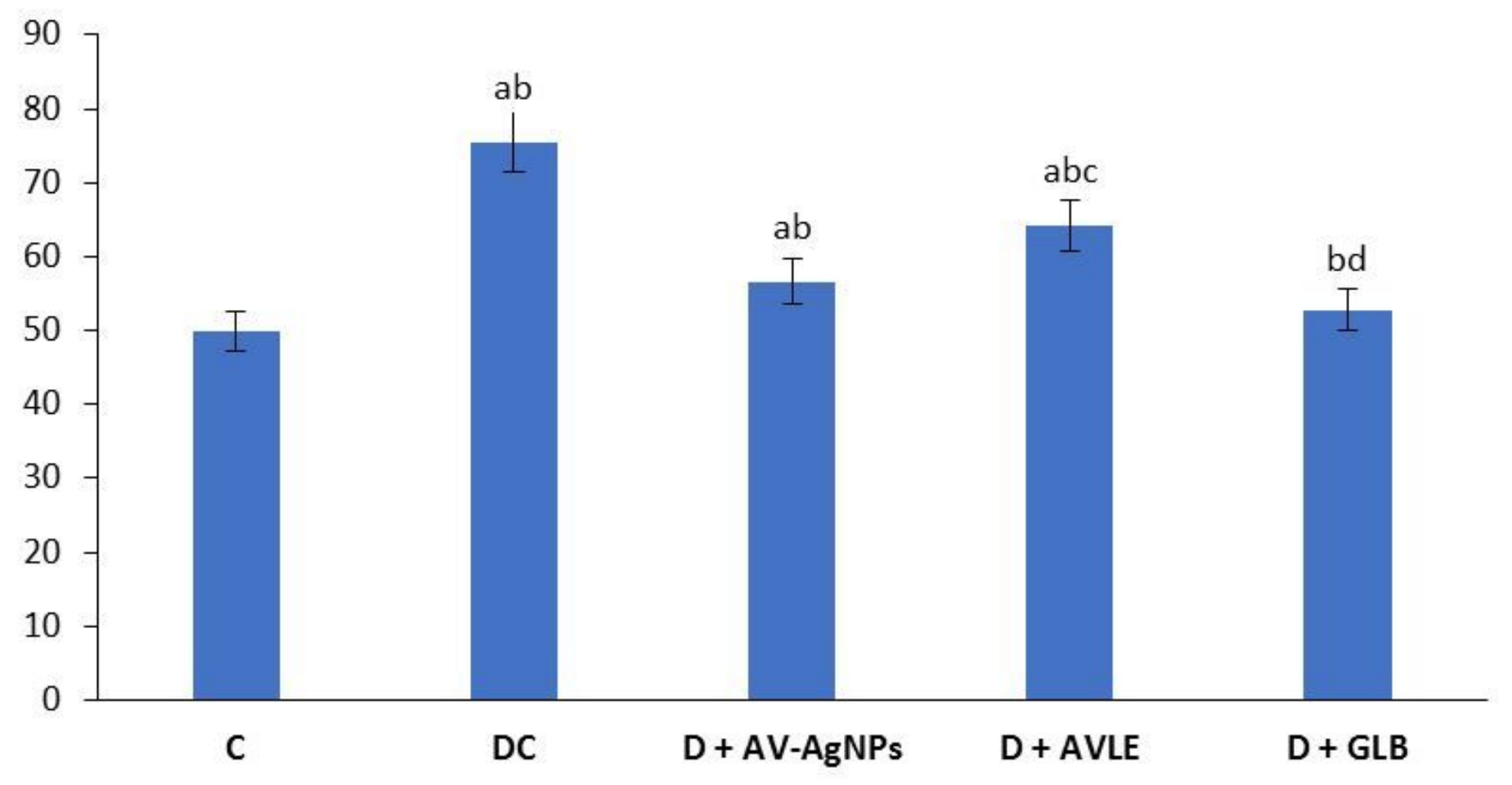

Figure 1 
Effects of AV-AgNPs Treatment on Hepatic MDA. Data presented as mean \pm SD $(n=10)$, groups compared with a control; $b$ diabetic control; $c$ D+AV-AgNPs; $d$ D+AVLE, e D+GLB; result considered significant when $p<0.05$ using ANOVA (One-way) followed by post hoc test (Tukey's).

\section{Hepatic SOD (U/gm of tissue)}

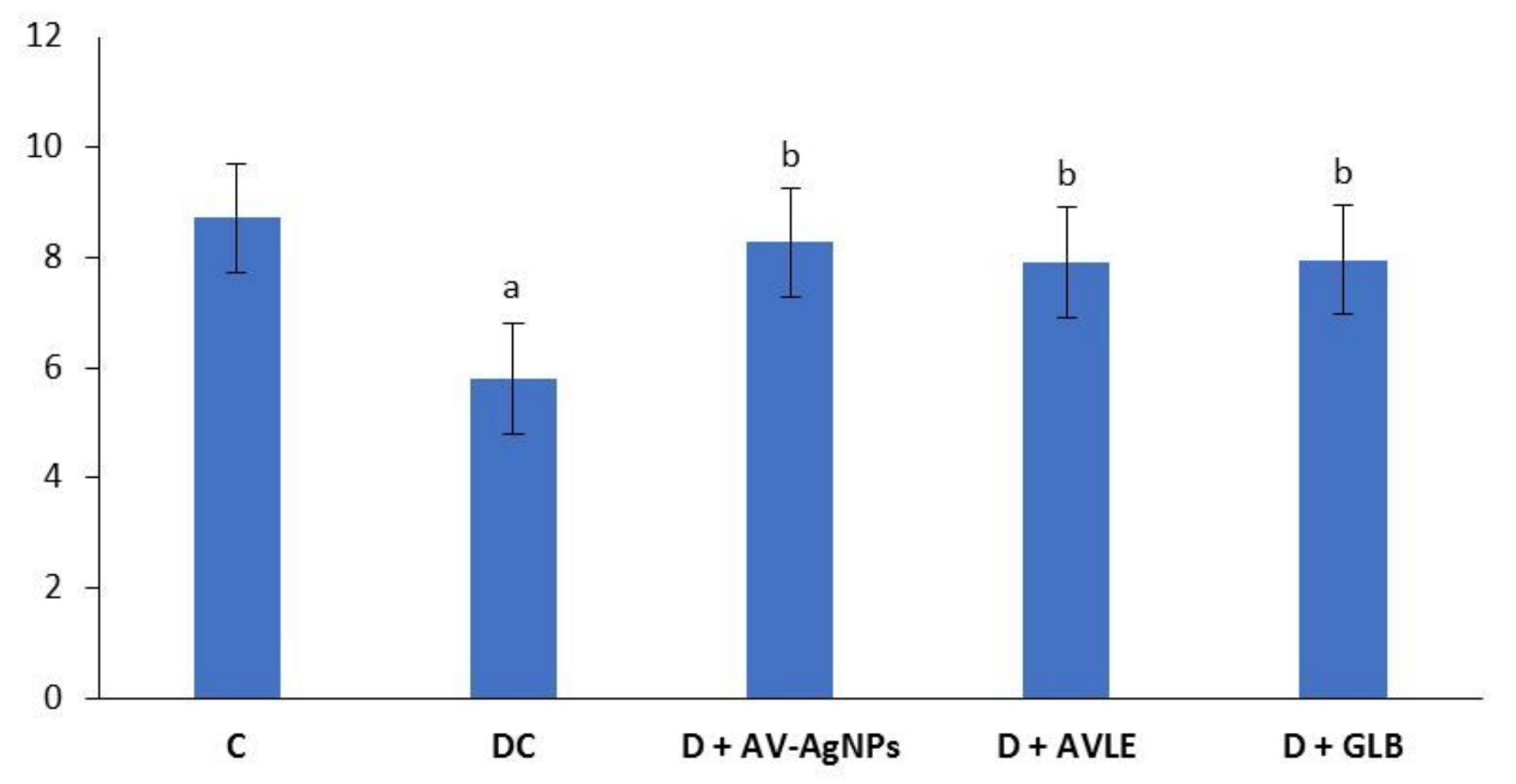

Figure 2

Effects of AV-AgNPs Treatment on Hepatic SOD. Data presented as mean \pm SD $(n=10)$, groups compared with a control; b diabetic control; c D+AV-AgNPs; d D+AVLE, e D+GLB; result considered significant when $p<0.05$ using ANOVA (One-way) followed by post hoc test (Tukey's). 


\section{Hepatic CAT (nmol/gm of tissue)}

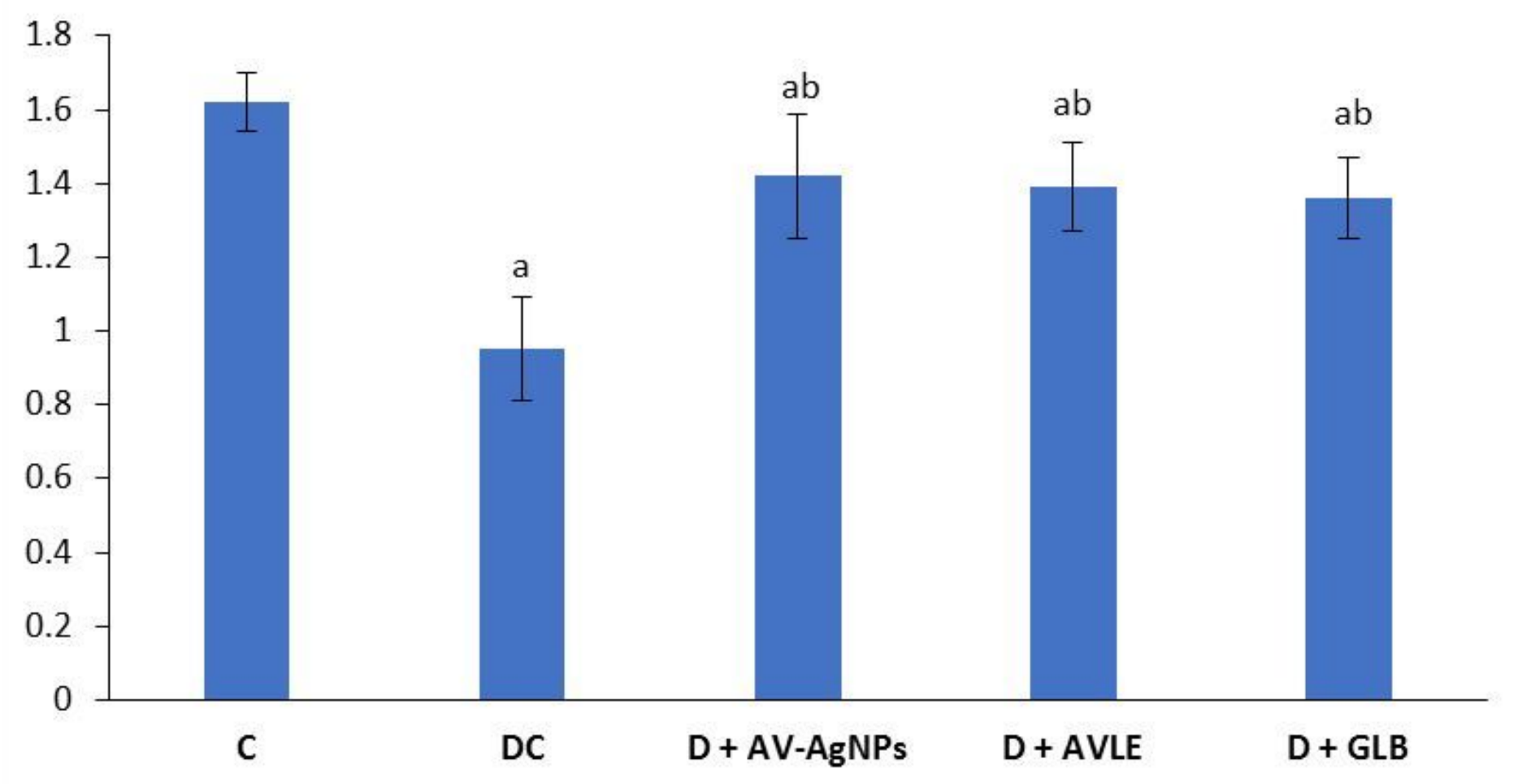

Figure 3

Effects of AV-AgNPs Treatment on Hepatic CAT. Data presented as mean \pm SD $(n=10)$, groups compared with a control; b diabetic control; c D+AV-AgNPs; d D+AVLE, e D+GLB; result considered significant when $p<0.05$ using ANOVA (One-way) followed by post hoc test (Tukey's). 


\section{Hepatic GSH (U/gm of tissue)}

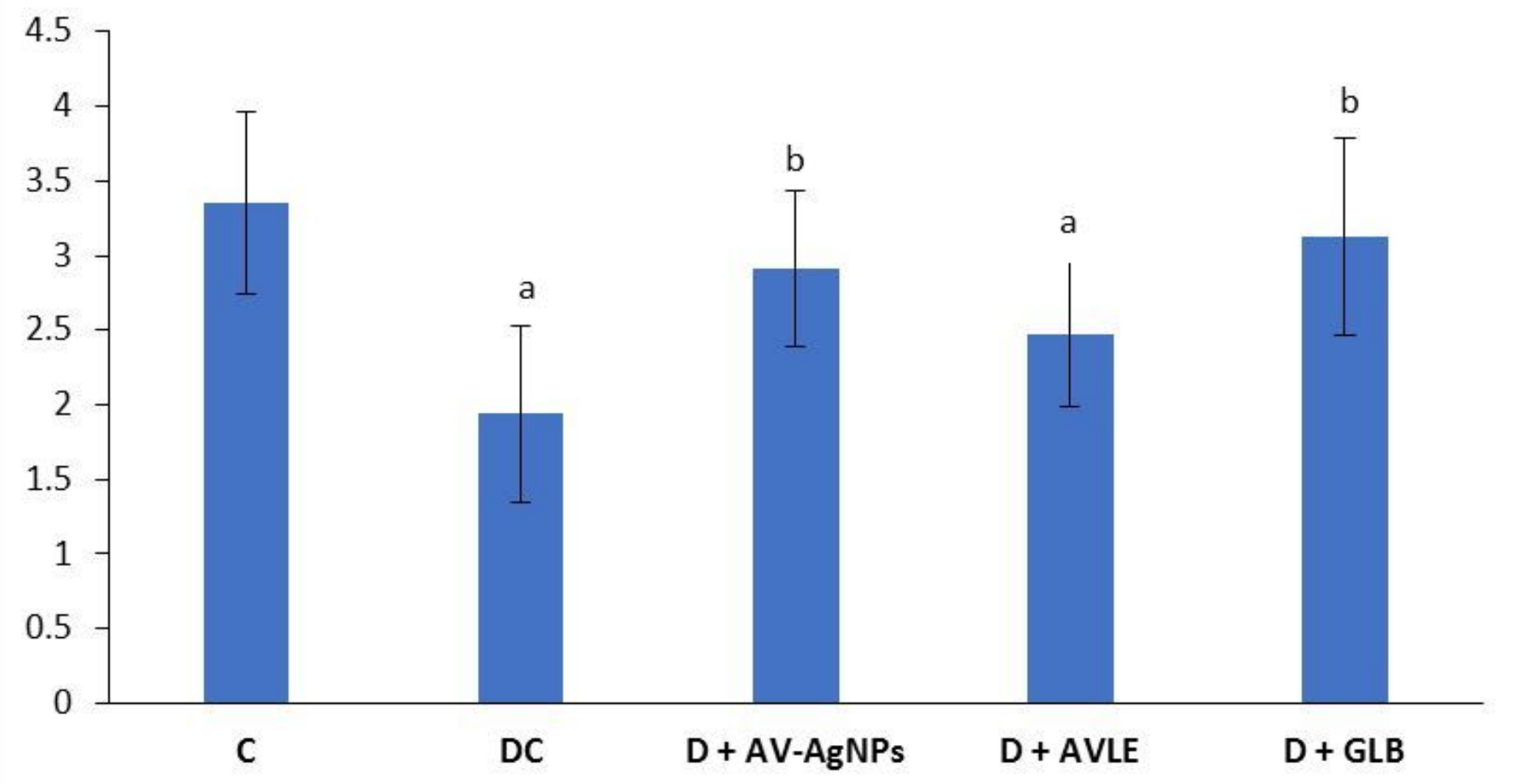

Figure 4

Effects of AV-AgNPs Treatment on Hepatic GSH. Data presented as mean \pm SD $(n=10)$, groups compared with a control; b diabetic control; c D+AV-AgNPs; d D+AVLE, e D+GLB; result considered significant when $p<0.05$ using ANOVA (One-way) followed by post hoc test (Tukey's). 

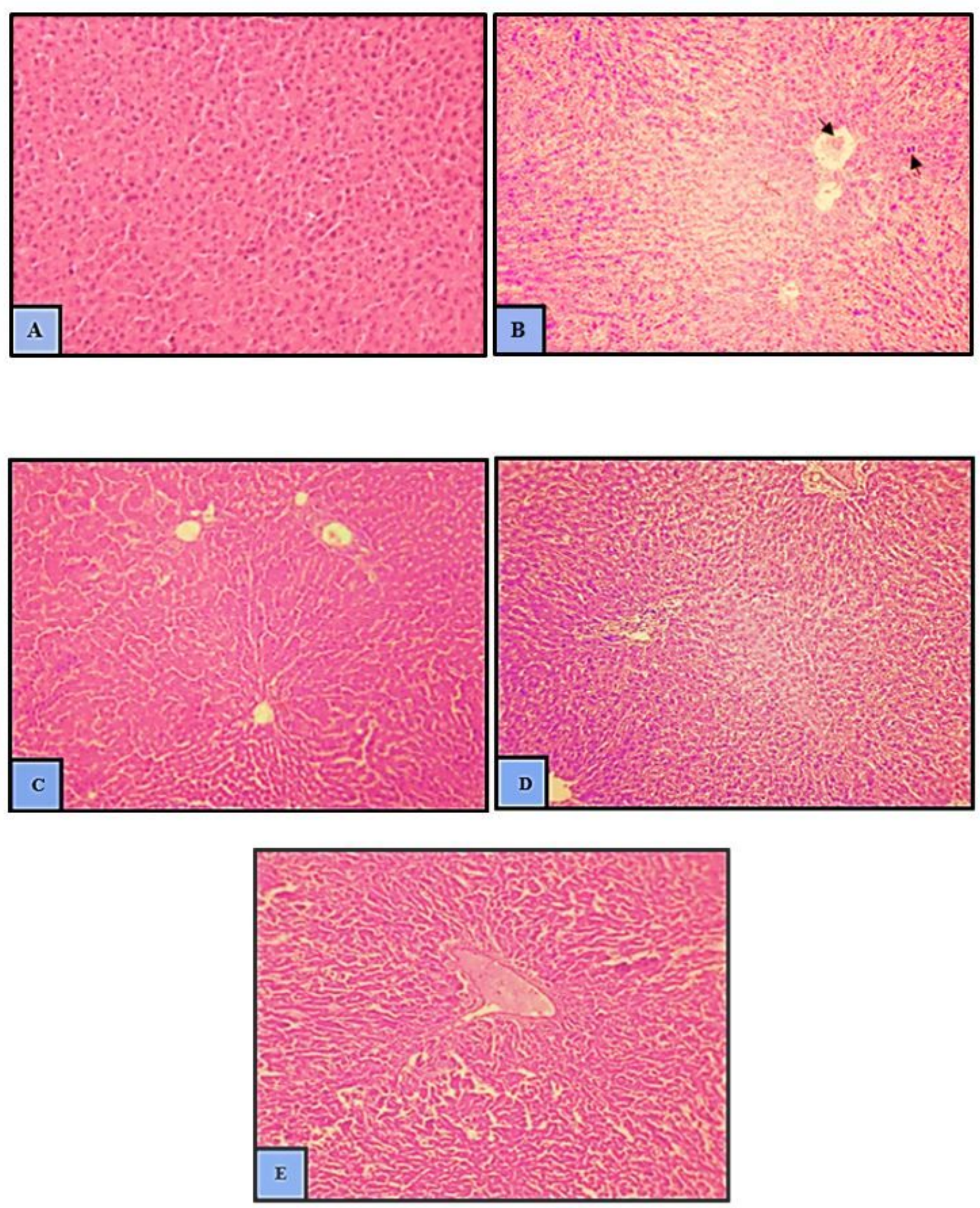

Figure 5(A-E).

Figure 5

(A-E). Effects of AV-AgNPs Treatment on Hepatic morphology (A) Control (B) Diabetic Control (C) D+AVAgNPs (D) D+AVLE (E) D+GLB

\section{Supplementary Files}


This is a list of supplementary files associated with this preprint. Click to download.

- GraphicalAbstract.docx 